\title{
Post-hoc Analysis on the CD14 C(-260)T Promoter Polymorphism and Coronary Heart Disease
}

\author{
M. PORSCH-ÖZCÜRÜMEZ ${ }^{1}$, J. HUCKE ${ }^{2}$, S. WESTPHAL ${ }^{2}$, J. A. HUBÁČEK ${ }^{1,3,4}$, \\ G. SCHMITZ ${ }^{1}$, C. LULEY ${ }^{2}$ \\ ${ }^{1}$ Institute for Clinical Chemistry and Laboratory Medicine, University of Regensburg, Germany, \\ ${ }^{2}$ Institute of Clinical Chemistry and Pathobiochemistry, Otto-von-Guericke-University, Magdeburg, \\ Germany, Institute for Clinical and Experimental Medicine and ${ }^{4}$ Cardiovascular Research Center, \\ Prague, Czech Republic
}

Received February 9, 2006

Accepted October 11, 2006

On-line available November 6, 2006

\begin{abstract}
Summary
Functional $\mathrm{C}(-260) \rightarrow \mathrm{T}$ polymorphism in the promoter of the CD14 gene has been reported to be associated with coronary heart disease (CHD). The functional role of the polymorphism, however, is still a matter of debate, since several studies have not proved its effect on clinical outcomes associated with atherosclerosis. Cardiovascular-related morbidity and mortality was assessed in a post-hoc approach four years after baseline characterization of patients (male/female $\mathrm{n}=36 / 32$ ) with angiographically proven coronary heart disease. CD14 C(-260) $\rightarrow$ T promoter genotype was determined at baseline. Seventeen out of $20 \mathrm{CHD}$ patients with non-lethal cardiovascular events carried at least one T-allele. CD14 T-260 allele carriers have a 3.59-fold (95\% confidence interval: 1.11-6.75) increased risk for non-lethal cardiovascular events (Kaplan-Meier plot: $\log$ rank test $p=0.029)$. All patients with lethal outcomes $(n=6)$ were also T-allele carriers. Multivariate logistic regression analysis among CHD patients including age, established risk factors and the $\mathrm{C}(-260) \rightarrow \mathrm{T}$ polymorphism as covariates and non-lethal events as a dependent variable confirmed the independent prospective effect of the T-allele on cardiovascular outcomes in this subset. Further evidence is provided for the role of $\mathrm{CD} 14 \mathrm{C}(-260) \rightarrow \mathrm{T}$ promoter polymorphism as a genetic susceptibility marker of atherosclerosis in patients with an advanced clinical course of the disease. Due to the small sample size and post-hoc character of the study large-scale prospective studies that monitor patients with proven CHD are needed to confirm these findings.
\end{abstract}

Key words

Atherosclerosis • CD14 • Genetics • Inflammation

\section{Introduction}

The $\mathrm{T}$ allele at position -260 (sometimes referred to as position -159 according to the transcription starting site) of the CD14 lipopolysaccharide receptor gene (CD14) has recently been proposed as a risk factor for myocardial infarction (Hubáček et al. 1999, Unkelbach et al. 1999, Shimada et al. 2000, Hohda et al. 2003, Morange et al. 2005). This epidemiological evidence was further substantiated at the molecular level. Promoters containing the CD14/-260T sequence show an increase in activity, which is paralleled by a decreased affinity 
between the $\mathrm{Sp} 1,2$, and 3 proteins and the polymorphic GC box (LeVan et al. 2001). Increased promoter activity is accompanied by a higher surface expression of CD14 on primary monocytes in T/T homozygotes (Hubáček et al. 1999, Eng et al. 2004). The most important CD14 signaling co-receptor is the toll-like receptor 4 (TLR4), which activates, among others, the nuclear factor $\kappa \mathrm{B}$ $(\mathrm{NF}-\kappa \mathrm{B})$ inflammatory pathway. Besides its role in innate immunity and host defense, the proinflammatory cytokines expressed upon TLR4/NF- $\mathrm{B}$ pathway activation exert proatherogenic effects (Kiechl et al. 2003). In addition, highest binding of enzymatically degraded low density lipoproteins is achieved by a subset of monocytes with high CD16 and high CD14 expression (Kapinsky et al. 2001). Homozygous carriers of the $\mathrm{T}$ allele have a significant increase in serum levels of SCD14 and a concomitant decrease in total serum IgE (Baldini et al. 1999), suggesting that CD14 may also play a role in the regulation of IgE synthesis and IgE-mediated diseases such as allergy and asthma. Recently, there have been several reports that associated CD14 C(-260) $\rightarrow \mathrm{T}$ promoter polymorphism to a variety of other diseases that possess an immunopathogenic component (Shih et al. 2005, Chao et al. 2005, Meiler et al. 2005). Inconsistent results were also published about the association between this variant and plasma cholesterol levels (Eilertsen et al. 2003, Hubáček et al. 2004).

However, several reports have not supported the association between this polymorphism and cardiovascular events (Nauck et al. 2002, Koch et al. 2002, Longobardo et al. 2003). Only a few prospective studies have been published, but these are also conflicting. Morange et al. (2004) did not find any association between the CD14 $\mathrm{C}(-260) \rightarrow \mathrm{T}$ promoter polymorphism and coronary heart disease (CHD) events, while Elghannam et al. (2000) observed a higher incidence of new coronary occlusions in the $\mathrm{C} / \mathrm{C}$ genotype group. Shimada et al. (2004) observed a higher rate of in-stent restenosis in patients with T/T genotype.

Recently, the HIFMECH study revealed that the T/T genotype was associated with higher interleukin-6 levels in CHD patients but not in controls (Morange et al. 2005). It was postulated that a pronounced inflammatory situation as seen in CHD patients is necessary for demonstrating a phenotypic effect of polymorphism.

In order to obtain further evidence on the role of this putative CHD risk marker, we re-evaluated a set of patients with CHD four years after baseline characterization and assessed the effect of the CD14 C(-
$260) \rightarrow \mathrm{T}$ promoter polymorphism on cardiovascular events recorded over this period.

\section{Materials and Methods}

\section{Subjects}

CHD patients were defined as individuals with a significant stenosis of $>50 \%$ of at least one main branch of the coronary arteries. The underlying coronary angiography was performed no longer than two years before baseline. Current smokers, subjects with malignancies, renal, hepatic or thyroid diseases or those treated with immunosuppressive or cytotoxic drugs were excluded. The participants were recruited during an eightmonth period. All individuals were Caucasians living in or near the City of Magdeburg. All baseline characteristics of the cohort were reported when the study was launched (Porsch-Oezcueruemez et al. 1999).

Out of 69 patients initially recruited, 68 patients (male/female: $\mathrm{n}=36 / 32$ ) could be reinvestigated after four years. Cardiovascular-related morbidity and mortality was recorded and CD14 C(-260) $\rightarrow$ T promoter genotype was determined from frozen DNA samples isolated at baseline. Non-lethal cardiovascular events recorded comprised myocardial infarctions, stent implantations, coronary artery bypass grafts, significant deterioration of angina pectoris, or significant aggravation of coronary stenoses which appeared after a secondary angiographic intervention.

The approval of the local ethics board and informed consent of the participants were obtained before the study.

\section{Laboratory analyses}

DNA was isolated from whole blood drawn at baseline, amplified and digested with HaeIII as formerly reported (Hubáček et al. 1999). Lipids, lipoproteins and fibrinogen were measured according to standard protocols as recently described (Porsch-Oezcueruemez et al. 1999).

Table 1. Allele and genotype frequencies of the $\mathrm{C}(-260) \rightarrow \mathrm{T}$ CD14 promoter polymorphism in patients with angiographically proven coronary heart disease.

\begin{tabular}{|c|c|c|c|c|}
\hline \multicolumn{2}{|r|}{$\begin{array}{l}\text { Allele frequency } \\
\qquad(2 n=136)\end{array}$} & \multicolumn{3}{|c|}{$\begin{array}{l}\text { Genotype frequency } \\
\qquad(n=68)\end{array}$} \\
\hline $\mathrm{T}$ & 0.412 & $\mathrm{~T} / \mathrm{T}$ & $16.2 \%$ & $\mathrm{n}=11$ \\
\hline \multirow[t]{2}{*}{$\mathrm{C}$} & 0.588 & $\mathrm{C} / \mathrm{T}$ & $50.0 \%$ & $\mathrm{n}=34$ \\
\hline & & $\mathrm{C} / \mathrm{C}$ & $33.8 \%$ & $n=23$ \\
\hline
\end{tabular}


Table 2. Distribution of established risk factors among patients with angiographically proven coronary heart disease stratified by T-allele carrier status referring to the CD14 C $(-260) \rightarrow T$ promoter polymorphism.

\begin{tabular}{lcccc}
\hline & Overall & $\begin{array}{c}\text { CHD patients } \\
\text { T-allele (a) }\end{array}$ & No T-allele (b) & $\begin{array}{c}\text { p-values } \\
\text { (a) vs. (b) }\end{array}$ \\
\hline Male/Female ratio [n] & $36 / 32$ & $21 / 24$ & $11 / 12$ & 0.928 \\
Age [years] & $63.5 \pm 8.1$ & $62.2 \pm 8.9$ & $66.2 \pm 5.6$ & 0.084 \\
Body mass index [kg/m²] & $28.7 \pm 4.2$ & $29.2 \pm 4.6$ & $28.1 \pm 3.3$ & 0.384 \\
Systolic blood pressure [mm Hg] & $148 \pm 21$ & $150 \pm 22$ & $150 \pm 20$ & 0.780 \\
Diastolic blood pressure [mm Hg] & $87 \pm 14$ & $88 \pm 16$ & $86 \pm 7$ & 0.895 \\
Total cholesterol [mmol/l] & $6.7 \pm 1.3$ & $6.6 \pm 1.7$ & $6.2 \pm 1.1$ & 0.504 \\
Triglycerides [mmol/l; (95\% C.I.)] & $1.8(0.9-4.3)$ & $1.9(0.9-4.3)$ & $1.7(0.7-3.8)$ & 0.291 \\
LDL-cholesterol [mmol/l] & $4.4 \pm 1.3$ & $4.5 \pm 1.5$ & $4.2 \pm 0.9$ & 0.861 \\
HDL-cholesterol [mmol/l] & $1.4 \pm 0.4$ & $1.4 \pm 0.4$ & $1.4 \pm 0.3$ & 0.756 \\
Lipoprotein (a) [mg/dl; (95\% C.I.)] & $16.9(1.1-150)$ & $17.4(1.4-133)$ & $16.3(1.1-150)$ & 0.871 \\
Fibrinogen [mg/dl] & $358 \pm 74$ & $355 \pm 73$ & $362 \pm 76$ & 0.609 \\
Ex-smoker [\% (n)] & $48.5(33)$ & $53.3(24)$ & $39.1(9)$ & 0.394 \\
Diabetes mellitus [\% (n)] & $48.4(30)$ & $46.2(18)$ & $52.2(12)$ & 0.845 \\
\hline
\end{tabular}

Data are mean \pm S.D. or $95 \%$ confidence interval [C.I.], respectively, as indicated.

\section{Statistical analysis}

The Statistical Package for the Social Science (SPSS for Windows 6.01) was employed for statistical analysis. Non-parametric Mann-Whitney U test was used for comparing the distribution of a variable between two unrelated groups. The Chi-square test was performed in case of categorical data. Survival curves depicted as Kaplan-Meier plots were compared by log rank tests. $\mathrm{P}<0.05$ values were considered as significant.

\section{Results}

The distribution of genotypes and allele frequencies are given in Table 1. Patients were further classified into those with no T-allele and those carrying at least one T-allele (T-allele carriers, Table 2). Average age of patients without the T-allele tended to be higher (mean \pm S.D., $66.2 \pm 5.6$ years) than in T-allele carriers $(62.2 \pm$ 8.9 years), but without statistical significance $(p=0.084)$. Among these two subgroups there were neither differences in the prevalence of the established risk factors hypertension, obesity (BMI $>30 \mathrm{~kg} / \mathrm{m}^{2}$ ), diabetes mellitus, and history of former smoking nor in the distribution of triglycerides, total cholesterol, LDLcholesterol, HDL-cholesterol, lipoprotein (a) and fibrinogen at baseline (Table 2).

During the follow up period, 6 lethal and 20 non-lethal cardiovascular events occurred. All deceased participants were T-allele carriers (Fig. 1A). However, due to the small sample size the log rank test did not reach statistical significance. Non-lethal cardiovascular events significantly prevailed among T-allele carriers $(n=17$, Fig. 1B). A predominant portion of these events was observed in the fourth year after baseline.

Multivariate logistic regression analysis of CHD patients was performed by entering the above mentioned established risk factors and age simultaneously in the model together with the T-allele carrier status as covariates and non-lethal cardiovascular events as dependent variable. The CD14 promoter polymorphism remained statistically significant $(p=0.031)$, while age and established risk factors did not significantly affect non-lethal outcomes in patients with coronary heart disease. Non-lethal events were also equally distributed among the two genders. As an exception, the BMI was significantly associated with non-lethal outcomes $(p=$ 0.019). Interestingly, patients with lower BMI were more prone to cardiovascular events. An average BMI of 27.1 $\mathrm{kg} / \mathrm{m}^{2}$ was observed in CHD patients with a cardiovascular event within the observation period, while patients without further events were significantly more obese (BMI $=29.5 \mathrm{~kg} / \mathrm{m}^{2} ; \mathrm{p}=0.030$ ).

\section{Discussion}

Several studies investigated the association 


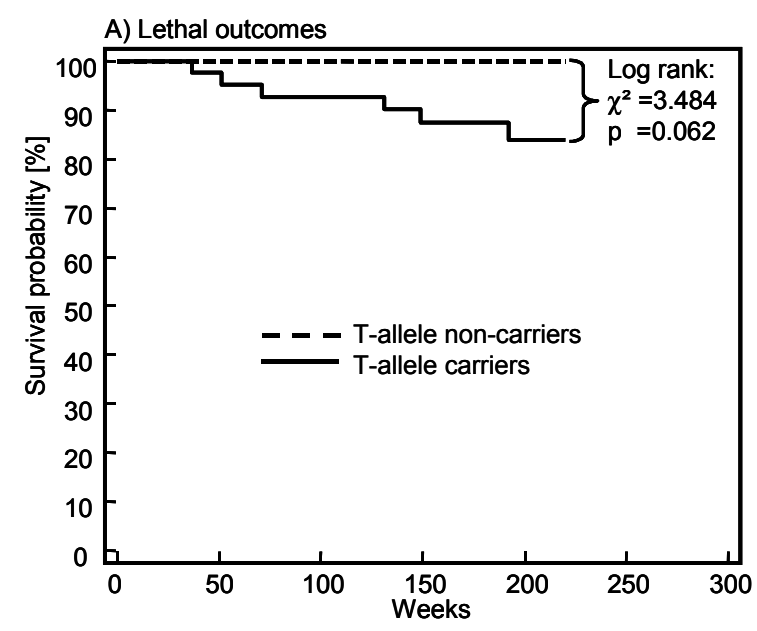

B) Non-lethal cardiac events

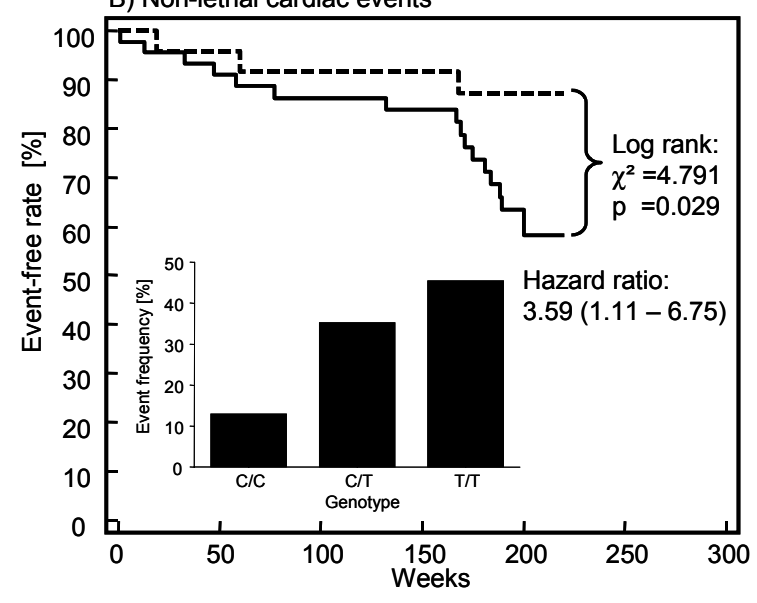

Fig. 1. Kaplan-Meier plots depict the time course and log ranks of $(A)$ lethal outcomes $(n=6)$ and (B) non-lethal cardiac events $(n=20)$. Patients with angiographically proven coronary heart disease were subdivided in T-allele carrier $(n=45$; solid lines) and non T-allele carrier ( $n=23$; broken lines) according to the CD14 $\mathrm{C}(-260) \rightarrow T$ promoter polymorphism.

between the CD14 $\mathrm{C}(-260) \rightarrow \mathrm{T}$ promoter polymorphism and different forms and states of atherosclerosisassociated diseases (Unkelbach et al. 1999, Hubáček et al. 1999, Nauck et al. 2002, Hohda et al. 2003, Shimada et al. 2004, Shin et al. 2005, Morange et al. 2005, Chao et al. 2005). These reports are inconsistent as far as the impact of the CD14 promoter polymorphism on atherogenesis and its clinical correlates is concerned. Functional studies on the cellular and subcellular level have proven that the $\mathrm{C}(-260) \rightarrow \mathrm{T}$ substitution influences the binding of the transcription factors SP1 and SP3 and increases thereby the surface expression of lipopolysaccharide receptor CD14 (Hubáček et al. 1999, Eng et al. 2004). Furthermore, the genotype-dependent expression of CD14 monocytes is associated with a significantly higher secretion of TNF- $\alpha$ after stimulation with Chlamydia trachomatis lipopolysaccharide (Kondo et al. 2003, Eng et al. 2004). Monocytes with high CD14 and CD16 surface expression are more prone to transform to foam cells during incubation with enzymatically modified LDL (Kapinsky et al. 2001). Both, increased proinflammatory properties and the susceptibility of defined monocyte subsets to store cholesterol are major pathophysiologic elements in the current concept of atherogenesis. Thus, a growing body of experimental evidence implicates that the single nucleotide polymorphism in the CD14 promoter might contribute to the polygenic susceptibility towards atherogenesis in humans.

Cross-sectional studies focused on differences of the genotype and allele distributions between patients with different clinical manifestations of cardiovascular diseases and healthy controls. Some reports have not confirmed the initial findings of Hubáček et al. (1999) who observed that the T-allele prevailed in CHD patients. The sample included males randomly selected from the Czech population as controls and survivors of myocardial infarction (MI) up to 22 months ago. In contrast, other studies compared preselected samples, in which both patients and controls underwent coronary angiography before recruitment. In a simultaneously published study the CD14 promoter polymorphism was associated with a history of myocardial infarction after excluding persons with hypertension and smokers (Unkelbach et al. 1999). The total study group was not matched for established risk factors, which significantly discriminated between patients and controls in the multivariate logistic regression analysis.

According to recent findings of Morange et al. (2005) a higher level of inflammation seen in CHD patients might be necessary to observe allele-specific phenotypic effects. This report motivated us to re-evaluate our own records. The dataset is, however, limited by the relatively small number of individuals included and the post-hoc character of the study design. The definition of cardiovascular end-points summarized a variety of clinical outcomes that do not comply with criteria applied to prospective studies. Nevertheless, our dataset provides the opportunity to obtain an insight into the phenotype of the CD14 $\mathrm{C}(-260) \rightarrow \mathrm{T}$ promoter polymorphism in a sample of $\mathrm{CHD}$ patients with commonly established CHD risk factors.

None of these risk factors contributed to the odds of non-lethal cardiovascular events, while the CD14 $\mathrm{C}(-260) \rightarrow \mathrm{T}$ promoter polymorphism remained 
significant. The follow up records of CHD patients revealed that all 6 deceased patients (Fig. 1A) and 17 out of 20 CHD patients (Fig. 1B) carried at least one T-allele. There was a linear association between the event frequency and the genotype (Fig. 1B, insert) suggesting a dominant effect of the T-allele. Shimada et al. (2004) recently reported that the rate of in-stent restenosis after elective coronary stenting was significantly associated with the CD14 promoter polymorphism genotype and that the inclusion of serum levels of solubilized CD14 in the model further enhanced the predictive impact even in a multivariate approach.

It is noteworthy that young children with Kawasaki's disease carrying the T/T CD14 promoter genotype develop significantly more complications due to coronary artery lesions (Nishimura et al. 2004). The Kawasaki disease is an acute, self-limited vasculitis in childhood. Coronary artery aneurysms have been shown to consist of CD8 T lymphocytes, macrophages, and IgA plasma cells, consistent with an immune response to an intracellular pathogen (Newburger and Fulton 2004).

These data imply that the effect of the CD14 promoter polymorphism is enhanced in patients with advanced atherosclerosis or a high inflammatory burden. An elevated load of activated macrophages might be a precondition that leads to an enhanced stimulus in the course of atherogenesis in T-allele carriers. This effect might be superimposed by an impact of established traditional risk factors in earlier states of atherosclerosis.

We conclude that, even though our data have to be interpreted with caution, our study is in line with recent studies that provided evidence for a role of the $\mathrm{CD} 14 \mathrm{C}(-260) \rightarrow \mathrm{T}$ promoter polymorphism as a genetic susceptibility marker of atherosclerosis. In particular, the effect of the T-allele might be more pronounced in patients with an advanced clinical stage of the disease. Due to the limited sample size and the post-hoc character of the study design larger prospective studies have to be initiated in order to confirm the impact of the CD14 $\mathrm{C}(-260) \rightarrow \mathrm{T}$ promoter polymorphism on the outcome of patients with advanced CHD.

\section{Acknowledgements}

JAH was supported by the project No. 1M0510 (MHYE of the Czech Republic).

\section{References}

BALDINI M, LOHMAN IC, HALONEN M, ERICKSON RP, HOLT PG, MARTINEZ FD: A polymorphism* in the 5 ' flanking region of the CD14 gene is associated with circulating soluble CD14 levels and with total serum immunoglobulin E. Am J Respir Cell Mol Biol 20: 976-983, 1999.

CHAO YC, CHU HC, CHANG WK, HUANG HH, HSIEH TY: CD14 promoter polymorphism in Chinese alcoholic patients with cirrhosis of liver and acute pancreatitis. World J Gastroenterol 11: 6043-6048, 2005.

EILERTSEN KE, OLSEN JO, BROX J, ØSTERUD B: Association of the $-159 \mathrm{C} \rightarrow \mathrm{T}$ polymorphism in the CD14 promoter with variations in serum lipoproteins in healthy subjects. Blood Coagul Fibrinolysis 14: 663-670, 2003.

ELGHANNAM H, TAVACKOLI S, FERLIC L, GOTTO AM JR, BALLANTYNE CM, MARIAN AJ: A prospective study of genetic markers of susceptibility to infection and inflammation, and the severity, progression, and regression of coronary atherosclerosis and its response to therapy. J Mol Med 78: 562-568, 2000.

ENG HL, WANG CH, CHEN CH, CHOU MH, CHENG CT, LIN TM: A CD14 promoter polymorphism is associated with CD14 expression and Chlamydia-stimulated TNF alpha production. Genes Immun 5: 426-430, 2004.

HOHDA S, KIMURA A, SASAOKA T, HAYASHI T, UEDA K, YASUNAMI M, OKABE M, FUKUTA N, KUROSAWA T, IZUMI T: Association study of CD14 polymorphism with myocardial infarction in a Japanese population. Jpn Heart J 44: 613-622, 2003.

HUBÁČEK JA, ROTHE G, PIŤHA J, ŠKODOVÁ Z, STANĚK V, POLEDNE R, SCHMITZ G: C(-260) $\rightarrow$ T polymorphism in the promoter of the CD14 monocyte receptor gene as a risk factor for myocardial infarction. Circulation 99: 3218-3220, 1999.

HUBÁČEK JA, ŠKODOVÁ Z, ADÁMKOVÁ V, LÁNSKÁ V, VLASÁKOVÁ Z, POLEDNE R: Association of the $-159 \mathrm{C} \rightarrow \mathrm{T}$ polymorphism in the CD14 promoter with variations in serum lipoprotein levels in healthy subjects. Blood Coagul Fibrinolysis 15: 365-366, 2004. 
KAPINSKY M, TORZEWSKI M, BUCHLER C, DUONG CQ, ROTHE G, SCHMITZ G: Enzymatically degraded LDL preferentially binds to $\mathrm{CD} 14^{\text {high }} \mathrm{CD} 16^{+}$monocytes and induces foam cell formation mediated only in part by the class B scavenger-receptor CD36. Arterioscler Thromb Vasc Biol 21: 1004-1010, 2001.

KIECHL S, WIEDERMANN CJ, WILLEIT J: Toll-like receptor 4 and atherogenesis. Ann Med 35: 164-171, 2003.

KOCH W, KASTRATI A, MEHILLI J, VON BECKERATH N, SCHOMIG A: CD14 gene -159C/T polymorphism is not associated with coronary artery disease and myocardial infarction. Am Heart J 143: 971-976, 2002.

KONDO T, OHNO M, SHIMOKATA K, IINO S, INDEN Y, MUROHARA T, HIRAI M: CD14 promoter polymorphism is associated with acute myocardial infarction resulting from insignificant coronary artery stenosis. Heart 89: 931-932, 2003.

LEVAN TD, BLOOM JW, BAILEY TJ, KARP CL, HALONEN M, MARTINEZ FD, VERCELLI D: A common single nucleotide polymorphism in the CD14 promoter decreases the affinity of Sp protein binding and enhances transcriptional activity. J Immunol 167: 5838-5844, 2001.

LONGOBARDO MT, CEFALU AB, PEZZINO F, NOTO D, EMMANUELE G, BARBAGALLO CM, FIORE B, MONASTERO R, CASTELLO A, MOLINI V, NOTARBARTOLO A, TRAVALIS S, AVERNA MR: The $\mathrm{C}(-260)>\mathrm{T}$ gene polymorphism in the promoter of the CD14 monocyte receptor gene is not associated with acute myocardial infarction. Clin Exp Med 3: 161-165, 2003.

MEILER C, MUHLBAUER M, JOHANN M, HARTMANN A, SCHNABL B, WODARZ N, SCHMITZ G, SCHOLMERICH J, HELLERBRAND C: Different effects of a CD14 gene polymorphism on disease outcome in patients with alcoholic liver disease and chronic hepatitis C infection. World J Gastroenterol 11: 6031-6037, 2005.

MORANGE PE, TIRET L, SAUT N, LUC G, ARVEILER D, FERRIERES J, AMOUYEL P, EVANS A, DUCIEMETIERE P, CAMBIEN F, JUHAN-VAGUE I. PRIME STUDY GROUP: TLR4/Asp299Gly, CD14/C-260T, plasma levels of the soluble receptor CD14 and the risk of coronary heart disease: The PRIME Study. Eur J Hum Genet 12: 1041-1049, 2004.

MORANGE PE, SAUT N, ALESSI MC, FRERE C, HAWE E, YUDKIN JS, TREMOLI E, MARGAGLIONE M, DI MINNO G, HAMSTEN A, HUMPHRIES SE, JUHAN-VAGUE I; HIFMECH STUDY GROUP: Interaction between the C-260T polymorphism of the CD14 gene and the plasma IL- 6 concentration on the risk of myocardial infarction: the HIFMECH study. Atherosclerosis 179: 317-323, 2005.

NAUCK M, WINKELMANN BR, HOFFMANN MM, BOHM BO, WIELAND H, MARZ W: C(-260)T polymorphism in the promoter of the CD14 gene is not associated with coronary artery disease and myocardial infarction in the Ludwigshafen Risk and Cardiovascular Health (LURIC) study. Am J Cardiol 90: 1249-1252, 2002.

NEWBURGER JW, FULTON DR: Kawasaki disease. Curr Opin Pediatr 16: 508-514, 2004.

NISHIMURA S, ZAITSU M, HARA M, YOKOTA G, WATANABE M, UEDA Y, IMAYOSHI M, ISHII E, TASAKI H, HAMASAKI Y: A polymorphism in the promoter of the CD14 gene (CD14/-159) is associated with the development of coronary artery lesions in patients with Kawasaki disease. J Pediatr 143: 357-362, 2003.

PORSCH-OEZCUERUEMEZ M, KUNZ D, KLOER HU, LULEY C: Evaluation of serum levels of solubilized adhesion molecules and cytokine receptors in coronary heart disease. J Am Coll Cardiol 34: 1995-2001, 1999.

SHIH HH, LIN TM, CHUANG JH, ENG HL, JUO SH, HUANG FC, CHEN CL, CHEN HL: Promoter polymorphism of the CD14 endotoxin receptor gene is associated with biliary atresia and idiopathic neonatal cholestasis. Pediatrics 116: 437-441, 2005.

SHIMADA K, WATANABE Y, MOKUNO H, IWAMA Y, DAIDA H, YAMAGUCHI H: Common polymorphism in the promoter of the CD14 monocyte receptor gene is associated with acute myocardial infarction in Japanese men. Am J Cardiol 86: 682-684, 2000.

SHIMADA K, MIYAUCHI K, MOKUNO H, WATANABE Y, IWAMA Y, SHIGEKIYO M, MATSUMOTO M, OKAZAKI S, TANIMOTO K, KURATA T, SATO H, DAIDA H: Promoter polymorphism in the CD14 gene and concentration of soluble CD14 in patients with in-stent restenosis after elective coronary stenting. Int $J$ Cardiol 94: 87-92, 2004. 
UNKELBACH K, GARDEMANN A, KOSTRZEWA M, PHILIPP M, TILLMANNS H, HABERBOSCH W: A new promoter polymorphism in the gene of lipopolysaccharide receptor CD14 is associated with expired myocardial infarction in patients with low atherosclerotic risk profile. Arterioscler Thromb Vasc Biol 19: 932938, 1999.

\section{Corresponding author}

M. Porsch-Özcürümez, University of Regensburg, Institute of Clinical Chemistry and Laboratory Medicine, FranzJosef-Strauss Allee 11, 93042 Regensburg, Germany. Fax: +49 (0)941 944 6202. E-mail: mail@DrPorsch.de 